\title{
Once poor, always poor? Do initial conditions matter? Evidence from the ECHP \\ Version, December 2009
}

\author{
Eirini Andriopoulou ${ }^{1}$, Panos Tsakloglou ${ }^{2}$ \\ ${ }^{1}$ Dr Eirini Andriopoulou, Athens University of Economics and Business: peace@aueb.gr \\ ${ }^{2}$ Prof. Panos Tsakloglou, Athens University of Economics and Business and IZA: \\ panos@aueb.gr
}

\begin{abstract}
The paper analyzes the effects of individual and household characteristics on current poverty status, while controlling for initial conditions, past poverty status and unobserved heterogeneity in 14 European Countries for the period 1994-2000, using the European Community Household Panel. The distinction between true state dependence and individual heterogeneity has very important policy implications, since if the former is the main cause of poverty it is of paramount importance to break the "vicious circle" of poverty using income-supporting social policies, whereas if it is the latter anti-poverty policies should focus primarily on education, training, development of personal skills and other labour market oriented polices. The empirical results are similar in qualitative but rather different in quantitative terms across EU countries. State dependence remains significant in all specifications, even after controlling for unobserved heterogeneity or when removing possible endogeneity bias.
\end{abstract}

JEL Codes: I32, I38

Keywords: Poverty dynamics, EU, ECHP

\section{INTRODUCTION}

In the last decade, poverty dynamics research focuses on the issue of poverty state dependence. In other words, the main hypothesis to be examined is whether past poverty experiences determine current poverty status. This may happen, for instance, because poverty spells might result in depreciation of human capital and employment skills, causing low-pay or unemployment spells and finally increasing the duration of poverty spells or the frequency of poverty spells (poverty reoccurrence). If state dependence is 'genuine' then it is important to bring individuals out of poverty using social benefits policy. Nevertheless, the state dependence usually observed in dynamic panel data models may also be attributed to sorting effects in the sense that the individuals that escape poverty may posses certain observed (e.g. age, education level, employment status) or unobserved characteristics (willingness to escape poverty, cleverness, social networks, life attitudes) and, thus, differ in a systematic way from the individuals that remain poor. Consequently, when examining state dependence it is important to control for observed as well as unobserved heterogeneity. Furthermore, a positive result in terms of state dependence may also be due to the fact that individuals with a higher tendency to remain permanently poor may be over-represented in the sample (Cappellari and Jenkins 2004). Therefore, in the case of state dependence, controlling for the observed and unobserved determinants of initial poverty status (initial conditions) is also important.

In the current paper, we follow the methodology of Wooldridge (2005), which proposes a solution to handle the problem of endogeneity of the initial conditions, while controlling for unobserved heterogeneity at the same time. He suggests using a joint density distribution conditional on the strictly exogenous variables and the initial condition, instead of attempting to obtain the joint distribution of all outcomes of the endogenous variables. In this analysis, a multivariate random effects logit methodology has been applied for examining the issue of poverty state dependence in $14 \mathrm{EU}$ Member-States for the period 1994-2000 using the data of the European Community Household Panel (ECHP). 
In the next two sections, the issues of unobserved heterogeneity and initial conditions problem are discussed drawing evidence from previous studies in poverty, employment and lowpay dynamics. The European Community Household Panel is briefly presented in section 4 along with household income and poverty definitions. Section 5, analyzes the model to be applied and also refers to the econometric details of the analysis. The last two sections present the empirical results and the conclusions of our analysis, along with some policy implications.

\section{TRUE STATE DEPENDENCE VERSUS UNOBSERVED HETEROGENEITY}

True state dependence means that the experience of poverty in one year per se raises the risk of being poor also in the next year (Heckman 1981a). However, individuals with "favourable" characteristics such as better motivation to escape poverty, intelligence, social networks, and positive life attitude might leave poverty earlier and consequently the state or duration dependence ${ }^{1}$ observed in data may not be genuine. Therefore it is important along with the effect of time to control also for observed as well as unobserved heterogeneity.

In the last decade, researchers more consciously try to distinguish between true state dependence and individual heterogeneity. This distinction has very important policy implications. For instance, if true state dependence is indeed significant compared to the individual heterogeneity, then it is important to break the "vicious circle" of poverty and try even at high cost to bring individuals out of poverty using social benefits policy. On the contrary, if individual heterogeneity defines the duration of poverty then anti-poverty policies should focus on other schemes such as education, development of personal skills and capacities or other labour market and social policies.

Most studies find that poverty state dependence remains significant even when controlling for unobserved heterogeneity. Canto (1996) examines the duration dependence for poverty entries and exits in Spain using a non-parametric specification for the hazard rate. She controls for unobserved heterogeneity indirectly by testing the homogeneity of the hazard rate between groups which are likely to have different spell lengths. She finds significant duration dependence both for poverty re-entries and exits. Cappellari and Jenkins (2004) using data from the BHPS for the 1990s conclude that there is substantial state dependence in poverty, separately from the persistence caused by heterogeneity. Poggi (2007) studies social exclusion dynamics in Spain and also finds that both individual heterogeneity and true state dependence are related to the probability of experiencing social exclusion. Biewen (2003) finds that even after controlling for observed and unobserved individual characteristics, there is negative state dependence in poverty exit and re-entry behaviour. He also calculates that $6 \%$ of the German population has unobserved characteristics that lead to low poverty exit and high re-entry rates, therefore making these individuals possible candidates for chronic poverty.

On the other hand, Giraldo et al. (2002) highlight that there are two sources of unobserved heterogeneity related to the study of poverty: first the ability of household members to obtain income in a specific period and second the way which this ability evolves over time. This is the main difference with previous analysis that assume that unobserved characteristics are time-invariant. When allowing for time-variant unobserved heterogeneity, the authors do not find any sign of true state dependence in their analysis of persistent poverty in Italy. This finding reinforces the theory of incentives of the poor which may vary not only among individuals but also with time.

As underlined by Aassve et al. (2006), there is also another issue on whether it is poverty experience or low income experience that really affects individuals with regards to the duration

\footnotetext{
${ }^{1}$ State and duration dependence are often used in the literature are synonyms. However, state dependence determines how the probability to be poor in the current period depends on whether someone is poor in the previous period, while duration dependence indicates how the probability to be poor in the current period depends on the duration spent in the poverty spell. This means that when duration dependence is examined, more than one lagged values of the dependent variable are used in the regression, or when poverty exit or re-entries are examined (instead of poverty status per se) more than one period dummies are included in the hazard function. This paper focuses on state dependence as defined in this paragraph.
} 
dependence. Poverty spells are not like unemployment spells, during which the individual is completely aware of the situation and his choices and preferences might be affected from his position. Studies that focus on low pay instead of poverty (Stewart and Swaffield 1999; Cappellari 2004) find that the probability of being low paid depends strongly on low pay in the previous year. In the same line, Finnie and Gray (2002), when examining individual mobility across earning quintiles, conclude that the probability of having an upward or downward transition depends negatively on the elapsed time that an individual has spent in a given quintile and this negative duration dependence remains significant when controlling for unobserved heterogeneity. On the contrary, the observed negative duration dependence in the exit rate proves to be more often spurious in unemployment studies (Cockx and Dejemeppe 2005).

\section{THE INITIAL CONDITIONS PROBLEM}

The initial conditions problem, developed by Heckman (1981b), in terms of transitions analysis, can be summarised to the fact that those who are poor in the first year of the survey may be a non-random sample of the population. Specifically, a positive result in terms of state dependence may be due to the fact that individuals with a higher tendency to remain permanently poor may be over-represented in the sample (Cappellari and Jenkins 2004). Therefore, in the case of state dependence, controlling for the observed and unobserved determinants of initial poverty status is important.

Practically, the problem arises because the start of the observation period does not concise with the start of the stochastic process that has generated the poverty or non-poverty experiences. Arulampalam et al. (2000) highlight that even if the model controls for unobserved heterogeneity, in order to disentangle the effect of state dependence from unobserved heterogeneity, the initial conditions need to be modelled instead of assumed as exogenously given, because the initial conditions may be correlated with the unobservables.

The issue of initial conditions has been tackled more extensively in the literature of unemployment dynamics. Arulampalam et al. (2000) examine unemployment dynamics for men using the BHPS and introduce the econometric issues concerning the dynamic panel data models: unobserved heterogeneity (based on Chamberlain 1984), state dependence (based on Heckman 1981a, 1981c) and the initial conditions problem (based on Heckman 1981b). Even when controlling for initial conditions and unobserved heterogeneity, they find that there is strong state dependence especially for older unemployed individuals that may be attributed to depreciation of human capital, signalling (in the sense that past unemployment spells signal the capacities or productivity of individuals for future employees) and to the fact that unemployed individuals may accept low quality jobs and this may lead to enterprise closure and future unemployment spells. Arulampalam (2002) extents the above work further in various directions, using different definitions for unemployment.

Cappellari and Jenkins (2004) use first-order Markov model in order to study poverty transitions $s^{2}$. The great virtue of this model, which is a complement to hazard and covariance structure models, is that it allows to control for initial conditions effects. In addition, these models control for potential non-random sample retention (for individuals that do no attrite and for whom at least two consecutive household incomes are observed). Models that control for initial conditions are also used in studies of earnings mobility rather than poverty (Stewart and Swaffield 1999; Cappellari 2004).

The methodology that we use in this paper in order to control for initial conditions is based on Wooldridge (2005), which proposes a solution to handle the problem of endogeneity of the initial conditions, while controlling for unobserved heterogeneity at the same time. He suggests using a joint density distribution conditional on the strictly exogenous variables and the

\footnotetext{
${ }^{2}$ Also Schluter (1997) uses a Markov model with exogenous variables in order to study the German income mobility with some extensions to poverty dynamics and Van Kerm (1998) studies low income turnover in the region of Wallonia in Belgium using Markov chain models. For a discussion of advantages and disadvantages of these models see Jenkins and Van Kerm (2000).
} 
initial condition, instead of attempting to obtain the joint distribution of all outcomes of the endogenous variables (Hsiao 1986). For the binary response models of probit and logit form, the main advantage of this method is that it can be applied easily using standard random effects software. Yet, the explanatory variables included in the model must be strictly exogenous and at most one $\mathrm{lag}^{3}$ of the dependent variable can be used in the estimation. Another restriction of the model is that it can be applied only to balanced panel data. This reduction from unbalanced to balanced panel data can always result in discarding useful information. For an application of this methodology to social exclusion see Poggi (2007) .

\section{THE EUROPEAN COMMUNITY HOUSEHOLD PANEL AND DEFINITIONS}

The empirical research of the current paper is based on the data of the European Community Household Panel (ECHP) produced by the Living Conditions Unit (E-2) of the Social and Regional Statistics and Geographical Information System Directorate (E) of EUROSTAT in Luxembourg. The European Community Household Panel (ECHP) can be defined as a harmonized cross-national longitudinal survey, which focuses on income and living conditions of households and individuals in the European Union. Due to its multidimensional nature ECHP provides information at micro-level across countries and across time on: income, employment, health, education, housing, migration, social transfers and social participation, as well as demographics. In other words, as Eurostat describes it, ECHP offers data on EU social dynamics (Eurostat 2003b). The duration of the survey is eight years, thus ECHP consists of eight waves, one for each year, from 1994 to 2001. The ECHP covers all the 15 Member-States of the EU in that period, but not all countries have participated in all waves. In addition some Member-States as the UK and Germany used data from existing panel surveys and converted them to ECHP format. In the current paper, we use all eight waves of the ECHP for $14 \mathrm{EU}$ Member-States ${ }^{4}$.

Most of the income components in the ECHP have an annual time frame of the calendar year preceding the interview. In all the ECHP countries, apart from the UK, the calendar year coincides with the tax year, which is the reference period for income components. Although, in this way income comparability is ensured, other variables like the household composition variables, the economic activity status etc. refer to the time of interview and might not relate well to income measured over a period up to twelve months in the past (Eurostat 2001). This is particularly undesirable for poverty dynamic analysis that tries to identify changes in income components and also uses the lag poverty status as an explanatory variable. Therefore for the needs of the dynamic analysis that follows, we have reconstructed the household income, transferring all the income components one year back ${ }^{5}$.

Following the practice of Eurostat, the poverty line used in the current thesis is set at $60 \%$ of the national median equivalised household income per capita, as it has been calculated using the modified OECD scale which assigns 1 to the first adult, 0.5 to the next adults and 0.3 to children.

\section{THE MODEL AND ECONOMETRIC DETAILS OF THE ANALYSIS}

The main difference of this model with a typical hazard model examining state dependence is that the dependent variable is the poverty status per se (whether someone is poor or non-poor) and not a variable signalling the poverty entry or exit. Moreover, state dependence

\footnotetext{
${ }^{3}$ D' Addio and Honore (2002) claim that the probability of exiting poverty may depend not only on the poverty status of the last period, but on the poverty status in the two most recent periods and they model second order state dependence, while controlling time-varying explanatory variables.

${ }^{4}$ For Sweden only cross-sectional data are available therefore Sweden has been excluded from the analysis.

${ }^{5}$ It should be underlined that we do not simply lag one wave back the total net household income, but we take into account the different composition that each household might had in the previous have. The methodology developed for the reconstruction of household income follows the logic of Eurostat's (2003a) construction of household income variable and is similar to the one applied by Debels and Vandecasteele (2008). The algorithm for the reconstruction of household income is available from the authors on request.
} 
is not captured with time dummies, but with the lagged value of the dependent variable. According to Wooldridge (2005, p. 42), only one lag of the dependent variable can be used when controlling for initial conditions. Nevertheless, this means that we cannot measure duration dependence, how much the chances of exiting poverty fall the longer one is in poverty ${ }^{6}$. Initial conditions are captured by introducing in the regression the value of the dependent variable in the first period. In this way, The assumption of exogeneity of all the explanatory variables is a strong assumption and therefore is tested at the end of the analysis.

More specifically for a random individual in the population and $t=1,2, \ldots \mathrm{T}$, the conditional probability that poverty occurs is:

$$
P\left(y_{i t}=1 \mid y_{i, t-1}, \ldots, y_{i 0}, z_{i}, c_{i}\right)=\Phi\left(z_{i t} \gamma+\rho y_{i, t-1}+c_{i}\right)
$$

Where $y_{i t}$ is the dependent variable or the poverty state of the individual $i$ at period $t$ (when $y_{i t}=1$ the individual is poor in period $t$ and when $y_{i t}=0$ the individual is non-poor), $\Phi(x)$ is the logistic function $\Phi(x)=\frac{\exp (x)}{1+\exp (x)}=\Lambda(x)$, which is between zero and one for all real numbers $x, \gamma$ and $\rho$ are the parameters to be estimated, $z_{i}$ and $z_{i t}$ are the vectors of time constant and time-varying explanatory variables and $c_{i}$ is the unobserved effect. $\rho$ is the coefficient of the lag value of the explanatory variable and the indicator of state dependence. If $\rho>0$ being poor (non-poor) at $t-1$ increases the chances of being poor (non-poor) at $t$.

There are three main assumptions related to equation (1). First, the dynamics are first order, once $z_{i t}$ and $c_{i}$ are also conditioned on. Second, the unobserved effect is additive inside the standard normal cumulative distribution function $\Phi(x)$. Third, all time-constant and timevarying variables are strictly exogenous (Wooldridge 2005, p. 41).

By assuming that the unobserved effect follows a normal distribution given the initial poverty condition $y_{i 0}$ and the time-constant explanatory variables $z_{i}$ :

$$
c_{i} \mid y_{i 0}, z_{i} \approx \operatorname{Normal}\left(a_{0}+a_{1} y_{i 0}+a_{2} z_{i}, \sigma_{\alpha}^{2}\right)
$$

the parameters of equation (1) can be consistently estimated. $a_{1}$ offers information about the relationship between the unobserved effect and initial poverty status, while $\sigma_{\alpha}^{2}$ indicates the dispersion accounted by unobserved heterogeneity. According to (Wooldridge 2005, p. 46), the density functions occurring from equations (1) and (2)

$$
f\left(y_{i t}, \ldots, y_{i T} \mid \mathrm{y}_{\mathrm{i} 0}, z_{i}, c_{i} ; \gamma, \rho\right)=\Pi_{\mathrm{t}}\left\{\Phi\left(z_{i t} \gamma+\rho y_{i t-1}+c_{i}\right)^{y t} \cdot\left[1-\Phi\left(z_{i t} \gamma+\rho y_{i t-1}+c_{i}\right)\right]^{1-y t}\right\}
$$

can be specified in such a way that standard random effects ${ }^{7}$ software can be used for the estimation.

The above estimation can be applied only to balanced panels. Therefore, there is a loss of information by dropping individuals that are not present in all seven waves ${ }^{8}$, while selection and attrition problems might also be present. Nevertheless, the loss of information is compensated by the fact that Wooldridge's methodology allows selection and attrition to depend on initial conditions. Specifically, individuals with different initial poverty status are allowed to have different missing data probabilities. In this way, attrition is controlled for without being explicitly modelled as a function of initial conditions (Wooldridge 2005; Poggi 2007). Moreover, since we control for initial conditions, we do not restrict the sample to an inflow sample and we also include in our analysis all the left-censored cases that we would have to exclude if a typical hazard analysis was used.

\footnotetext{
${ }^{6}$ This effect can only be captured when modelling poverty exit with hazard functions using time dummies so as to capture the increasing effect of state dependence year by year.

${ }^{7}$ For the use of fixed effects when controlling for initial conditions in a different methodological framework see Hahn (1999). For a full discussion of the advantages of random effects versus fixed effects see Honore and Kyriazidou (2000) and Honore (2002).

${ }^{8}$ Six for Austria and Luxembourg and five for Finland.
} 
As in most poverty studies, since the equivalised household income per capita is used for the calculation of poverty status, it is indirectly assumed that the household members pool their income sources, therefore only personal characteristics of the household head are considered as regressors and not the personal characteristics of the household members (e.g. only the age of the household head is taken into account and not the age of each household member). Consequently, members of the same household have the same poverty determinants and thus the same poverty status. Since the panel includes repeated observations from the same individual and from the same family, the problem of possible violation of the homoskedasticity assumption is present. Therefore, we use the "robust" or "sandwich" estimators for the standard errors, which allow observations to be dependent within cluster, although they must be independent between clusters (see Huber 1967; White 1980). The results reported in the following tables have been calculated without the use of weights and are reported in terms of marginal effects ${ }^{9}$.

\section{EMPIRICAL RESULTS: ANALYSIS OF STATE DEPENDENCE CONTROLLING FOR INITIAL CONDITIONS}

We have developed four specifications using the dynamic logit model presented in the previous section. The first specification includes only the initial conditions dummy and the lagged value of the poverty status. In the second specification, variables controlling for the household and household head characteristics are included in the regression analysis, as well as. wave dummies in order to control for business cycles effects. In the third specification, certain variables that may have caused endogeneity bias are removed from the analysis, while in the fourth specification, the role of household type dummies is examined in detail. In order to facilitate comparisons across countries, the probability of the baseline group is reported on the top of each table.

In Table 1, the results for the first specification are reported. Both the marginal effects for the lagged poverty status and initial status are positive and significant at the $0,1 \%$ level in all 14 Member-States meaning that being poor in the initial or previous year increases the hazard of being poor in the current year. In most countries the initial conditions variable gives much higher marginal effects than the lag poverty status with the exception of Finland, the Netherlands and the UK, where the difference is small or goes to the opposite direction, showing that poverty reoccurrence is also an important issue. Specifically, the marginal effects for the initial conditions variable ranges from 11.3 to 38.6 in Greece, while in terms of absolute probability (the sum of the marginal effect and the baseline probability) ranges from 13.1 in the Netherlands to 43.7 in Greece. As suggested by the standard deviation of the heterogeneity variance, $\sigma_{\alpha, \text {, unobserved }}$ heterogeneity is large. Also, the likelihood ratio test for rho ${ }^{10}$ suggests that unobserved heterogeneity is statistically significant in all countries.

In specification 2 (Table 2), we include variables capturing certain characteristics of the household head and the household so as to control for the observed heterogeneity across individuals. Moreover, we add wave dummies in order to control for possible business cycle effects, especially for the time-varying variables such as the employment dummies. The baseline group consists of individuals that were not poor in the initial and previous year and live in a household with a male household head, aged [30,64], who has completed secondary education, is employed full-time and is a citizen of the country under examination. There are no dependent

\footnotetext{
9 The marginal effects report the difference between the probability that an event will occur when possessing a particular characteristic different from the baseline group (e.g. the difference in probability of being poor when living in a female-headed household instead of a male-headed household). The marginal effect can be positive if the probability is greater compared to the baseline group, or negative if the probability is lower. The total probability occurs when adding the marginal effect to the baseline probability. The marginal effects, thus, represent differences in probabilities and are reported using the interval $[0,1]$. In this paper, we multiply the marginal effects by 100 and thus reports them using the interval $[0,100]$ in order to avoid a large number of decimal digits, given the large number of countries included in the results.

${ }^{10}$ rho is the ratio of the heterogeneity variance to one plus the heterogeneity variance $r h o=\frac{\left(\text { sigma_u }^{2}\right.}{1+\left(\text { sigma_u }^{2}\right.}$ and in a way indicates how much of the model variance is due to unobserved heterogeneity.
} 
children ${ }^{11}$ in the household. None of the household members is unemployed and none of the household members has severe disability or chronic disease. The probability of being poor while belonging to the baseline group is around $1 \%$ to $2 \%$ in all countries with the exception of the Netherlands. The fact that there are not large differences in the baseline probability across countries, means that the choice of the baseline group is successful in facilitating comparisons across countries.

As expected, the effect of past poverty experiences decreases in almost all countries in comparison to specification 1, when the household and the household head variables are added in the regression. The absolute decrease in the marginal effects corresponding to the effect of initial conditions is greater than the decrease in the marginal effects of lagged poverty status. This is expected since the socioeconomic variables that are included in the regression may also in a way determine whether someone is poor at the first place.

Living in a household with a household head aged less than 30 or more than 64 increases the hazard of being poor in all countries. The effect is very strong for young headed households in Finland (5.5), the Netherlands (5.5.) and Denmark (4.6) as compared to the baseline group. Households headed by elderly individuals have a higher risk to be in poverty in 8 out of 14 countries and the highest marginal effect appears in Denmark (1.7) and Greece (1.2). Netherlands and France are the only countries where the chances to be in poverty significantly decrease for individuals living with household heads aged more than 64, as compared to the baseline group. The vulnerability of female-headed households to poverty is not evident in all countries. In Finland (0.8), France (0.4) and Germany (0.3) and Italy (0.2) the marginal effect is significantly positive, but slightly above zero. In Portugal, living in a female-headed household significantly decreases the probability of being poor $(0.2)$.

The level of education of the household head also plays an important role in determining the chances of being in poverty at a particular point in time. Living in a household with a household head who has completed higher education sharply decreases the chances of being poor, while household heads with primary education increase the odds of being in poverty in all countries but the Netherlands. As expected, unemployment and inactivity of the household head also increase the probability of poverty. The effect of unemployment is particularly strong in Ireland (11.4), the Netherlands (10.9), Belgium (9.7) and the UK (6.0) and that of inactivity in the Netherlands (7.4), Denmark (5.9), Ireland (5.1), Finland (4.1) amd the UK (4.1) ${ }^{12}$. The effect of citizenship of the household head is mixed across EU Member-States with a tendency to increase the probability of being poor both for the EU and the non-EU citizenship whenever the effect is significant. The highest risk of being poor while living in a household with an immigrant household head is observed in Finland; especially when the household head has a non-EU citizenship. The Netherlands and Belgium are the only countries where living with an immigrant household head (with an EU-citizenship in the first case and a non-EU citizenship in the second) seems to decrease the chances of being poor. Nevertheless, there are issues of possible underrepresentation of immigrants in the ECHP sample and, thus, the results concerning immigration variables should be tackled with care ${ }^{13}$.

\footnotetext{
${ }^{11}$ The dependent child in the ECHP is defined as an individual aged less than 16 or an individual aged 16-24 that lives with his parents in the same household and he is economically inactive.

${ }^{12}$ Yet, it should be underlined at this point that the above figures do not reflect absolute figures of individuals being under the poverty line, since this depends on the total distribution of income. It only presents how the hazard of being in poverty varies across different countries given different observed individual and household characteristics. The fact that in Greece being inactive does not increase so much the risk of being in poverty as in Finland does not mean that the level of poverty for the specific subgroup is higher in the later than the former country. The results must be interpreted relatively in comparison to the baseline group.

${ }^{13}$ In most countries, immigrants are undocumented and refuse to participate in surveys. Moreover, in the way that ECHP sample persons were selected, immigrants could only appear in the panel, if they were selected at the first wave or if they move in to a sample household in the next waves. Therefore, it can be alleged that ECHP does not measure properly the dynamics in the population occurring from immigration inflows.
} 
In all countries, the presence of dependent children in the household increases the chances of being poor with the exception of Denmark, where the effect is not significant ${ }^{14}$. This can be explained by the fact that in this country families with children are important recipients of social transfers ${ }^{15}$. The effect is particularly strong in the Netherlands, where the probability to be in poverty when living in a household with dependent children increases by 5.2 units as compared to the baseline group, by 2 in Spain and 1.8 in Italy. Having an unemployed (other than the household head) or a disabled household member in the household also increases the chances of being in poverty in the Member-States where the corresponding odds ratio is significant. The effect is particularly strong households with an unemployed household member in Italy and the Netherlands and disabled household members in Ireland.

The wave dummies give negative marginal effects in most cases that they are significant (with the exception of Portugal), indicating that in these waves as compared to the baseline wave (wave 1 -year 1994) the chances to be in poverty for the baseline group were lower per se.

In total, specification 2 (Table 2) fits much better than specification 1 (Table 1), since both the Akaike Information Criterion (Akaike 1973) and the Baysenian Information Criterion (Schwarz 1978) decrease ${ }^{16}$. Yet, as suggested by $\sigma_{\alpha}$ unobserved heterogeneity remains large and significant at the $0.1 \%$ level in all countries ${ }^{17}$.

According to Wooldridge (2005, p. 41), when applying the methodology described in section 5, for the estimators to be efficient, all time-constant and time-varying variables must be strictly exogenous. The strict exogeneity assumption means that since we control for the past poverty status and unobserved heterogeneity, current poverty status must be unrelated to the value of the regressors in past or future period. In other words, violation of the exogeneity assumption exists if there are feedback effects from poverty status to future values of the covariates included as regressors in the logit model. Individual characteristics such as age, gender and nationality cannot depend on past poverty status. For education this is likely to apply for the limited period of observation used here. Nevertheless, the existence of past poverty spells might theoretically affect the employment status, fertility decisions (existence of dependent children in the household), employment and health status of household members. When examining feedback effects, Biewen (2004) finds that there is evidence that experiencing poverty has a negative effect on future employment behaviour and on household cohesion.

In the literature, there is not any commonly accepted test for testing the exogeneity assumption. In Table 3, the variables that may cause endogeneity have been removed from the model. In total, six variables have been excluded from the model that are related to the employment status of the household head and the existence of dependent children, unemployed or disabled household members in the household. Both the Akaike Information Criterion (Akaike 1973) and the Baysenian Information Criterion (Schwarz 1978) decrease suggesting that the the explanatory power of the model has deteriorated. Moreover, unobserved heterogeneity increases meaning that the variables removed from the specification did belong to the observed heterogeneity across individuals that explain differences in the probability of being poor. Despite the fact that a large number of variables is removed from the specification, when comparing the results of Table 2 and Table 3 , we do not find differences in the estimates for all the variables that are common in both specifications. Yet, in some cases there are large differences e.g. for young

\footnotetext{
${ }^{14}$ When poverty transitions are examined, in Denmark and Finland the chances of exiting poverty increase, when dependent children are present into the household (the results are available from the author on request) (Andriopoulou 2008).

${ }^{15}$ In Denmark, the household income of a couple with two dependent children consists of $15,63 \%$ of social benefits (which is the lowest among all household types with dependent children). The relevant EU mean is 10,44\%, while the lowest figure is observed in Greece, where only $1 \%$ of household income of a couple with two dependent children comes from social benefits.

${ }^{16} \mathrm{AIC}$ and BIC can be used since the two model specifications have been used using the same dataset and the same estimation method (Singer and Willett 2003).

${ }^{17}$ I have also run the above three specifications using a standard logit regression without controlling for unobserved heterogeneity. What is interesting to note is that although the odds ratio for the household and household head characteristics are slightly higher when unobserved heterogeneity is not controlled for, the odds for the state dependence are much more higher while the odds for the initial conditions much lower. This suggests that when unobserved heterogeneity is not controlled for, there is an underestimation of the magnitude of initial conditions with respect to the poverty status in the previous year and vice-versa. The corresponding results are available from the authors on request.
} 
headed households in Denmark and Finland, for elderly households in Denmark and for immigrants with an EU citizenship in Spain and immigrants without an EU citizenhip in France, Finland and Luxembourg. This indicates that the increase in the marginal effect absorbed by the remaining variables is not distributed proportionally in all cases and that there might be some issues of endogeneity for specific countries that cannot be easily examined at this context of analysis (for an approach examining feedback effects see Biewen 2004).

Table 4 focuses on the role of household type on poverty. Various household type classifications have been tested in the regressions and the one finally chosen includes ten different household types: single adult aged less than 30; single adult aged from 30 to 64; single adult aged more than 64; couple only, where both members are aged less than 65; couple only with at least one household member aged more than 64; other type of household without dependent children (e.g. a couple with working children living together, two brothers living together, three students living together etc.); lone parent with at least one dependent child; couple with one or two dependent children; couple with more than two dependent children; other type of household with at least one dependent child (e.g. a couple with two dependent children and one grant-parent living together, two grandparents with a dependent grandchild etc.). When the household type dummies are used, the age dummies for the household head and the dummy indicating whether there are dependent children in the household are removed from the specification as they partly capture the same effect in a aggregate way. The baseline household is a couple without children and none of the household members is over 64 years old.

The probability of being poor when belonging to the baseline group ranges from 0.7 in Luxembourg to 3.5 in Ireland and it is slightly higher for 10 out of 14 countries and lower for 4 countries as compared to the results of Table 2. Both the marginal effects for the initial and the lagged poverty status are high and significant suggesting that past poverty experience determine current poverty status irrespectively of the "amount" of observed and unobserved heterogeneity that we control for.

Compared to the baseline household type, almost all other household types have higher probability to be in poverty with few exceptions. For instance single adults aged more than 64 in Spain and the Netherlands and the residual category "other household type without dependent children" in Ireland, Spain, Greece, Portugal and Italy have lower odds to be in poverty than the baseline group. With regards to the Mediterranean countries and Ireland it should be noted that in this residual category belongs the family type with two parents and adult children that work but still live in their parents household, which is very common in these Member-States. More than $20 \%$ of the population lives in such households in the Mediterranean countries, while the relevant figure is around $10 \%$ in the Netherlands, Finland and Denmark ${ }^{18}$.

Living alone and being less than 30 years old sharply increases the risk of being poor in most countries. In Portugal the effect is negative (-0.8), while in Spain, Greece, Ireland and Luxembourg the effect is insignificant. On the contrary, in the Northern countries such as the Netherlands (28.9), Finland (16.1), Denmark (10.4) and the UK (9.8), the increase in the probability to be poor, when living alone and being less than 30 years old, is particularly high. Being a single adult aged 30 to 65 years old increases the chances of being poor as compared to the baseline group only in 7 out of 14 countries and only in Ireland the marginal effect is greater than 2. Also in Ireland, single adults aged more than 64 have significantly higher chances to be in poverty (9.4), while the relevant marginal effect ranges from 1.0 to 1.9 in the remaining countries where the effect is positively significant. Netherlands is the only country where the effect is negative at $95 \%$ level of confidence. A couple with at least one member aged more than 64 has higher probability to be in poverty as compared to the baseline group in Greece (2.4), Austria (1.9), Denmark (1.9), Spain (1.1), Belgium (0.9), Portugal 90.8) and the UK (0.7); and significantly lower probability but small in magnitude in Germany $(-0.3)$ and France $(-0.3)$. As already mentioned the residual type of household without dependent children gives negative marginal effects in a substantial number of countries and only in the Netherlands (4.4) and Denmark (1.7), the chances to be under the poverty line are higher when living in such a household type.

\footnotetext{
${ }^{18}$ Own calculations from ECHP data
} 
In accordance with the previous results, all household types with dependent children have higher chances to be in poverty than the baseline group. The higher risk is found in loneparent families and families with more than two children. In particular, lone-parent families have much higher risk to be in poverty as compared to the baseline group in the Netherlands (18.3), the UK (8.4), Germany (4.6) and France (3.9), while families with more than two children have much higher probability to be under the poverty threshold in the Netherlands (11.6), Spain (6.1), Luxembourg (5.1), the UK (4.7) and Italy (4.4). It should be mentioned though that the share of the population belonging to this households type differs a lot from country to country and varies from $5.36 \%$ in Greece to $20.30 \%$ in Ireland.

The results for the variables that are common in specifications 2 and 4 are similar in magnitude and significance. Both the AIC and the BIC decline, as well as the measures of unobserved heterogeneity suggesting that this more analytic specification determines in a better way the probability to be in poverty in all countries examined.

For each value of the predictor in period $\mathrm{j}$ there is a postulated value of the logit hazard. In Table 5, the impact of past poverty experience (initial and in the previous year) on the conditional probability of being in poverty is estimated using specification 1 with and without controlling for unobserved heterogeneity. Table 6 , also, estimates the impact of state dependence on the conditional probability of being in poverty now averaged over the other covariates (specification 2). The estimation probabilities reveal that when we do not control for unobserved heterogeneity the effect of poverty in the previous year is much stronger than the initial poverty status. When unobserved heterogeneity is controlled the result is reversed.

The probabilities in both parts of Table 5 correspond to four combinations of past poverty status. In the first line, the probability of individual to experience poverty is estimated, when he/she is non-poor both in the initial and the previous year. When unobserved heterogeneity is taken into account, the probability to be in poverty in period $t$, while being non-poor in the initial year and in t- 1 declines to half in most Member-States. If the individual has experienced poverty in the past, either in the previous or initial year, the probability to be poor in $t$ increases as compared to the initial combination (non-poor in the initial period, non-poor in t-1). When I do not control for unobserved heterogeneity experiencing poverty in the previous year is a much stronger determinant than experiencing poverty in the initial year only. The probabilities are higher than 0.40 in all Member-States for the second combination (non-poor in the initial year, poor in the previous year,), while for the third combination poor in the initial year, non-poor in the previous year), the probabilities range from 0.09 in the Netherlands to 0.23 in Greece. Yet, this result is reversed, in Part B of Table 5, when unobserved heterogeneity is controlled for in almost all countries (except for Finland and the Netherlands). The probabilities for combination 2 range from 0.10 in Belgium to 0.36 in Finland, while for combination 3, the probabilities increase and range from 0.11 in Germany to 0.44 in Greece. Finally, the individuals that have experienced poverty both in the initial and the previous year have the highest probabilities to be in poverty in $t$ with or without controlling for unobserved heterogeneity. In the first case, the probabilities range from 0.53 in the Netherlands to 0.81 in Portugal and in the second case from 0.49 in the Netherlands to 0.80 in Portugal.

Table 6 estimates the relevant probabilities using specification 2 and, thus, a more favourable (with regards to poverty status) baseline group ${ }^{19}$. In general, all estimated probabilities are lower than in the previous table. Specifically, Part A of Table 6 (without unobserved heterogeneity) reveals that the probability of being poor in $t$ while being non-poor in the initial year of the survey and in the previous year ranges from 0.01 in Luxembourg to 0.05 in the

\footnotetext{
${ }^{19}$ The baseline group consists of individuals that were not poor in the initial and previous year and live in a household with a male household head, aged [30,64], which has completed secondary education, is employed full-time and is a citizen of the country under examination. There are no dependent children in the household. None of the household members is unemployed, none of the household members has severe disability or chronic disease and finally the household does not paying rent for household accommodation (either one of the household members owns the household or accommodation is provided for free). As the previous analysis indicates, in most cases, the probability of being in poverty is much lower for individuals belonging to the baseline group, than in other population groups that posses different household or household head characteristics.
} 
Netherlands. When the individual is non-poor in the initial year, but poor in the previous year (combination 2), the probability of being poor in $t$ increases sharply and ranges from 0.15 in Denmark to 0.41 in the Netherlands. The probabilities are much lower, when the individual appears to be poor in the initial year but non-poor in the previous year (from 0.03 to 0.12 ). Finally, when both the initial and lagged poverty values are 1, the probability of being poor ranges from 0.30 in Denmark to 0.63 in the Netherlands. In line with specification 1, when observed heterogeneity is controlled for (Part B of Table 6), the probabilities as well as the differences among Member-States decline. The probability of being poor in $t$, while being nonpoor in the initial year of the survey and in the year t- 1 ranges from 0.01 to 0.03 . This means that individual unobserved characteristics "absorb" part of the differences in predicted probabilities across Member-States. The probability of being poor in $t$, while being non-poor in the initial year, but poor in the previous year is now much lower (ranging from 0.05 in Denmark to 0.18 in the Netherlands) and lower than the corresponding probabilities for being poor in the initial year and non-poor in the previous year (ranging from 0.07 in Denmark to 0.16 in Austria). Finally, the probabilities of being poor in t, while being non-poor both in the initial year and in the year $t-1$ are on average 0.09 points lower than the probabilities without controlling for unobserved heterogeneity. The lowest value is 0.20 in Denmark and the highest 0.53 in the Netherlands.

The general conclusion to be drawn from these two tables is that, ceteris paribus, the probability of being in poverty now is higher for individuals that have experienced poverty in the past both with or without unobserved heterogeneity. When unobserved heterogeneity is added in the regression, probabilities decline and the effect of being poor only in the initial year (not the previous year) is higher than the effect of being poor only in the previous year (not the initial year).

\section{CONCLUSIONS}

The aim of this paper was to study the dynamics of poverty and in particular whether past poverty experience affects current poverty status. Our main conclusion is that state dependence remains significant in all specifications, even when controlling for observed, unobserved heterogeneity and initial conditions. Consequently, social benefits are likely to play an important role if breaking the "vicious circle" of poverty is among the main policy objectives of the policymakers.

We also find that the coefficient of initial poverty status is significant in all specification and when we control for unobserved heterogeneity the magnitude of the coefficient is higher that the magnitude of the coefficient of lag poverty status. This indicates that an early intervention is necessary. As Finnie (2000) underlines, given the state dependence and the intergenerational effect that poverty often has, an early intervention offers the maximum of benefits to the poor households and society, because there are greater chances for an early than a late intervention to have long-lasting effects.

Irrespectively of the magnitude of state dependence, unobserved heterogeneity remains also important in all specifications and its magnitude (as captured by sigma_a) does not decrease substantially as the specification of the model improves. Moreover, the results for the observed household and household head characteristics indicate that individual heterogeneity also affects current poverty status. Consequently, anti-poverty policies should include other schemes such as education, development of personal skills and capacities or other labour market and social policies. It is also important to note that having an income over or under the poverty line and, thus, being characterised as "poor" or "non-poor" is not directly observable from individuals (contrary to the unemployment situation for example) and may not affect the behaviour and choices of persons and families as strong as it would be necessary for escaping from poverty. Building good incentives for the poor people to work harder, take advantage of opportunities and exploit life-chances might also be necessary.

To conclude, the empirical results of this paper indicate that both state dependence and individual heterogeneity (observed or unobserved) play an important role in keeping individuals 
into poverty. Consequently, there is no single path into or out of poverty, suggesting that multiple policies can be considered to help people getting out of poverty. Given that the education and development of personal skills is a long-run process, which is also related to household income levels, the importance of the intervention of state in the short-run for breaking the "vicious cycle" should be emphasized.

\section{REFERENCES}

Aassve A, Burgess S, Dickson M, Propper C (2006) Modelling poverty by not modelling poverty: an application of a simultaneous hazards approach to the UK. CASE Discussion Paper Series No. 106, Centre for Analysis of Social Exclusion, London School of Economics, London

Akaike H. (1973) Information theory as an extension of the maximum likelihood principle. Paper presented at the Second International Symposium on Information Theory, Akademiai Kiado, Budapest

Andriopoulou E (2008) Poverty dynamics in the European Union:1994-2000. MIMEO of $\mathrm{PhD}$ Thesis, Department of International and European Economic Studies, Athens University of Economics and Business

Arulampalam W (2002) State dependence in unemployment incidence: evidence for British men revisited. IZA Discussion Paper Series No. 630, Institute for the Study of Labor, Bonn

Arulampalam W, Booth AL, Taylor MP (2000) Unemployment persistence. Oxford Economic Papers 52:24-50

Biewen M (2003) Who are the chronic poor? Evidence on the extent and the composition of chronic poverty in Germany. IZA Discussion Paper Series No. 779, Institute for the Study of Labor, Bonn

Biewen M (2004) Measuring state dependence in individual poverty status: are there feedback effects to employment decisions and household composition? IZA Discussion Paper Series No. 1138, Institute for the Study of Labor, Bonn

Canto-Sanchez O (1996) Poverty dynamics in Spain: a study of transitions in the late 1990s. Distributional Analysis Research Programme Discussion Papers No. 15, Suntory and Toyota International Centres for Economics and Related Disciplines (STICERD), London School of Economics, London

Cappellari L (2004) Earnings mobility among Italian low paid workers. IZA Discussion Paper Series No. 1068, Institute for the Study of Labor, Bonn

Cappellari L, Jenkins SP (2004) Modelling low income transitions. Journal of Applied Econometrics 19:593-610

Chamberlain G (1984) Panel data. In: Griliches S, Intriligator M (eds) Handbook of econometrics. North-Holland, Amsterdam

Cockx B, Dejemeppe M (2005) Duration dependence in the exit rate out of unemployment in Belgium. Is it true or spurious? Journal of Applied Econometrics 20:1-23

D' Addio AC, Honore BE (2002) Duration dependence and timevarying variables in discrete time duration models. Working paper No. 13, Department of Economics, School of Economics and Management, University of Aarhus, Aarhus

Debels A, Vandecasteele L (2008) The time lag in annual household-based income measures: assessing and correcting the bias. Review of Income and Wealth 54(1):71-88

Eurostat (2001) Reference periods. ECHP Documentation No. DocPAN E2/SEP/28/2001, European Commission, Eurostat, Social and Regional Statistics and Geographical Information System Directorate (E), Living Conditions Unit (E-2), Luxembourg 
Eurostat (2003a) ECHP UDB construction of variables: from ECHP questions to UDB variables. ECHP Documentation No. DocPAN 167/2003-12, European Commission, Eurostat, Social and Regional Statistics and Geographical Information System Directorate (E), Living Conditions Unit (E-2), Luxembourg

Eurostat (2003b) ECHP UDB manual: waves 1 to 8, survey years 1994-2001. ECHP Documentation No. DocPAN 168/2003-12, European Commission, Eurostat, Social and Regional Statistics and Geographical Information System Directorate (E), Living Conditions Unit (E-2), Luxembourg

Finnie R (2000) Low income (poverty) dynamics in Canada: entry, exit, spell durations, and total time. Working paper No. W-00-7E, Applied Research Branch, Strategic Policy, Human Resources Development Canada, Hull, Quebec

Finnie R, Gray D (2002) Earnings dynamics in Canada: an econometric analysis. Labour Economics 9:763-800

Giraldo A, Rettore E, Rivellato UT. (2002) The persistence of poverty: true state dependence or unobserved heterogeneity? Some evidence from the italian survey on household income and wealth. Paper presented at the 27th General Conference of the International Association for Research in Income and Wealth, Stockholm

Hahn J (1999) How informative is the initial condition in the dynamic panel model with fixed effects? Journal of Econometrics 93(1999):309-326

Heckman JJ (1981a) Heterogeneity and state dependence. In: Rosen S (ed) Studies in labor markets. Chicago Press, Chicago, Illinois

Heckman JJ (1981b) The incidental parameters problem and the problem of initial conditions in estimating a discrete time - discrete data stochastic process. In: Manski C, McFadden D (eds) Structural analysis of discrete data with econometric applications. MIT Press, Cambridge, Massachusetts

Heckman JJ (1981c) Statistical models for discrete panel data. In: Manski C, McFadden D (eds) Structural analysis of discrete data with econometric applications. MIT Press, Cambridge, Massachusetts

Honore BE (2002) Non-linear models with panel data. CEMMAP Working Paper No. 13, The Institute of Fiscal Studies, London

Honore BE, Kyriazidou A (2000) Panel data discrete choice models with lagged dependent variables. Econometrica 68(4):839-874

Hsiao C (1986) Analysis of Panel Data. Cambridge University Press, Cambridge

Huber PJ. (1967) The behaviour of maximum likelihood estimates under non-standard conditions. Paper presented at the Fifth Berkeley Symposium on Mathematical Statistics and Probability, University of California Press, Statistical Laboratory, University of California, California

Jenkins SP, Van Kerm P (2000) An empirical model of low income dynamics in Belgium. Working Paper, University of Essex and University of Namur, Colchester, Namur

Poggi A (2007) Does persistence of social exclusion exist in Spain? Journal of Economic Inequality 5:53-72

Schluter C (1997) On the non-stationarity of German income mobility (and some observations on poverty dynamics). Discussion Paper No. 30, Suntory and Toyota International Centres for Economics and Related Disciplines, London School of Economics, London

Schwarz G (1978) Estimating the dimensions of a model. Annals of Statistics 6:461-461

Singer JD, Willett JB (2003) Applied longitudinal data analysis: modeling change and event occurrence. Oxford University Press, Oxford

Stewart M, Swaffield J (1999) Low pay dynamics and transition probabilities. Economica 66(261):23-42 
Van Kerm P (1998) Low income turnover in Wallonia: evidence from the panel study on Belgian households. Working paper, Group de Recherche en Economie du BienEtre, Facultes Universitaires Notre-Dame de la Paix (FUNDP), Namur

White H (1980) A heteroskedasticity-consistent covariance matrix estimator and a direct test for heteroskedasticity. Econometrica 48(4):817-830

Wooldridge JM (2005) Simple solutions to the initial conditions problem in dynamic, nonlinear panel data models with unobserved heterogeneity. Journal of Applied Econometrics 20:39-54 


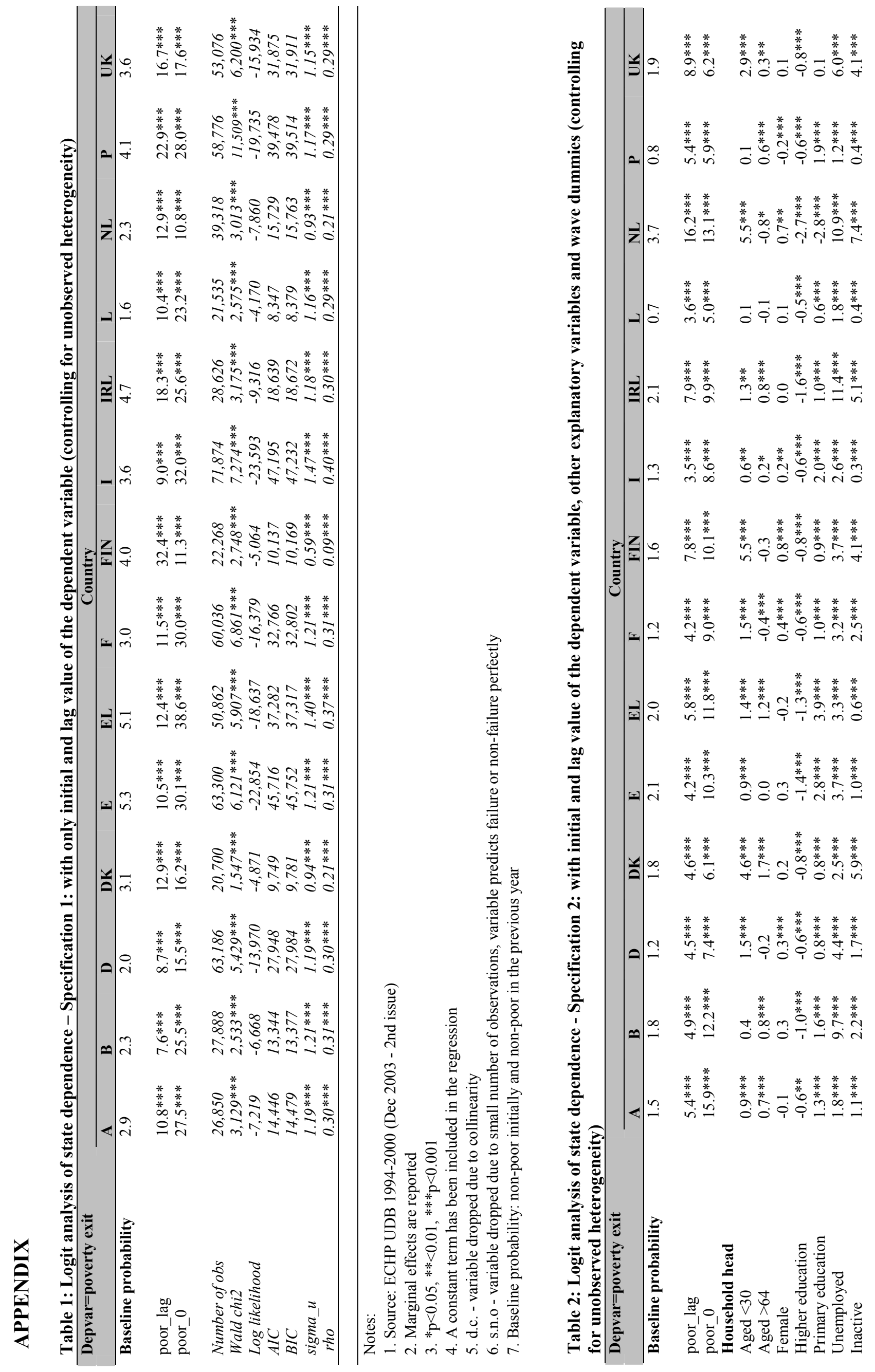




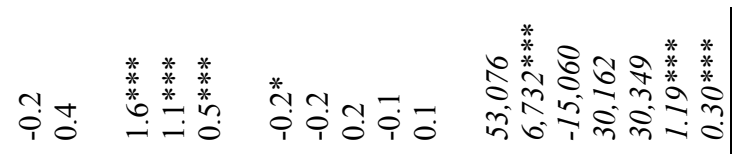

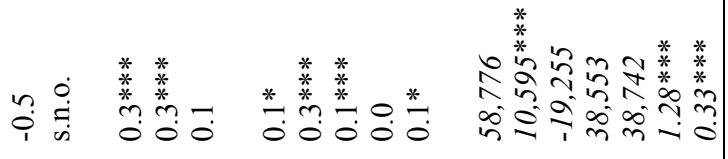

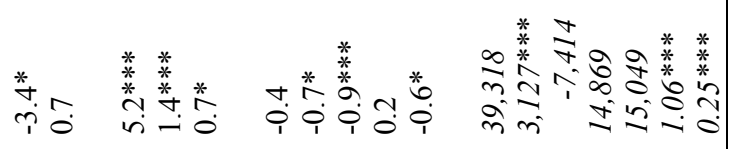

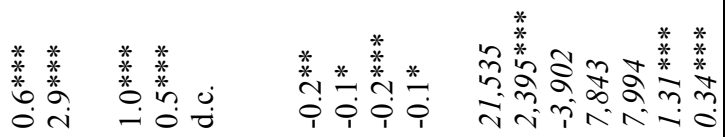

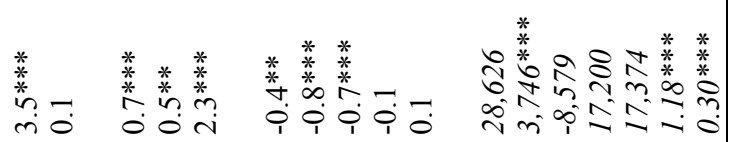

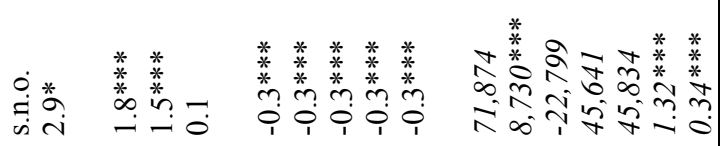

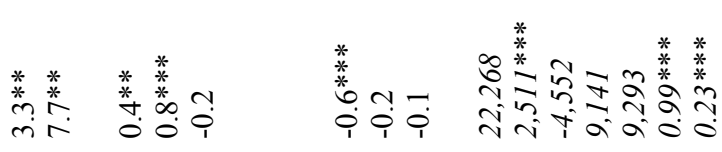

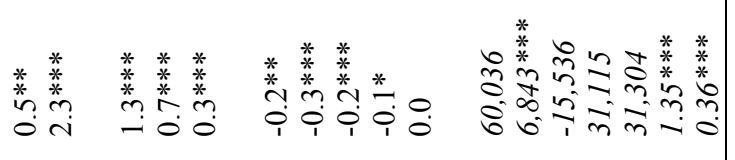

ơ

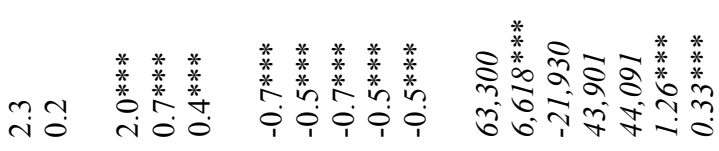

(4)

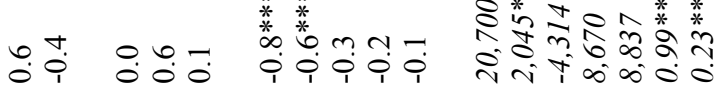

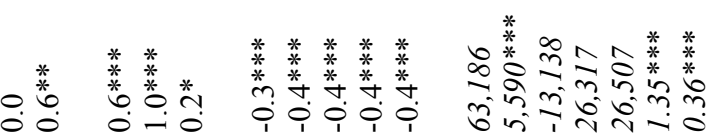

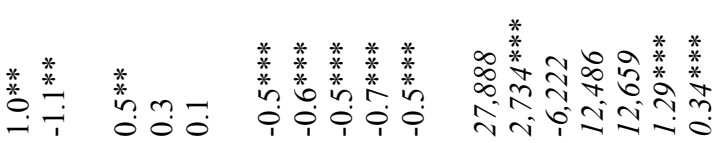

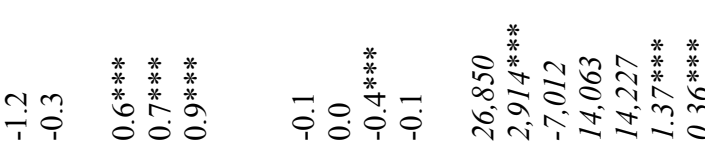

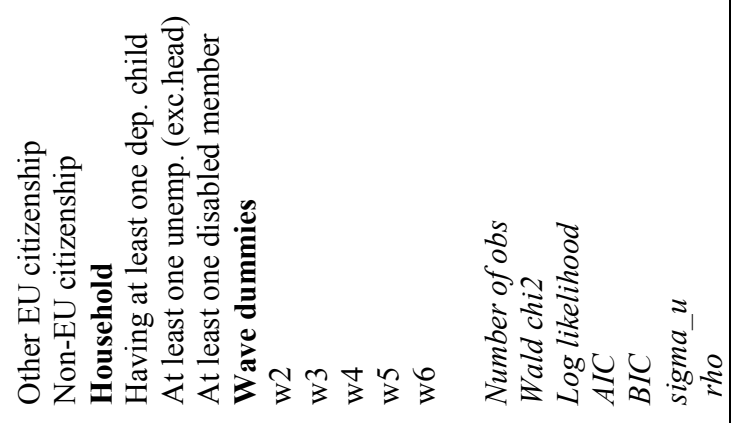

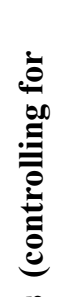

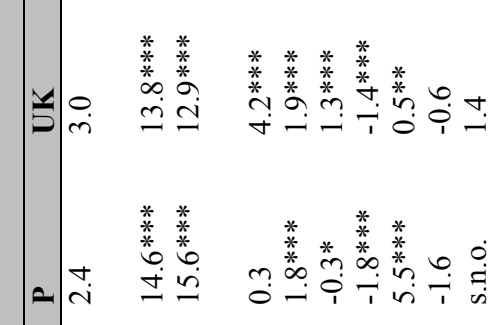

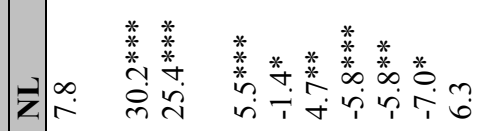

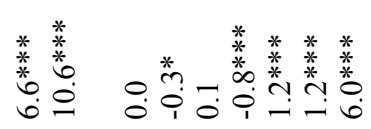

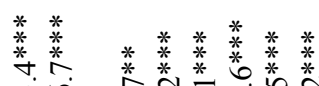

ڤึ

蒫

害.

善

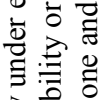

政

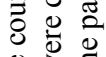

政

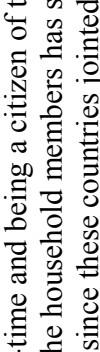

言艺。

可

무워

s.

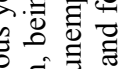

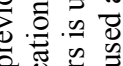

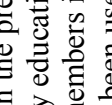

을 을

항흘 흥

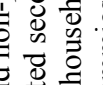

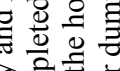

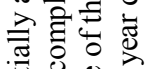

驾言

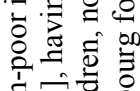

守

窟它

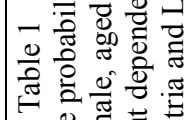

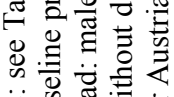

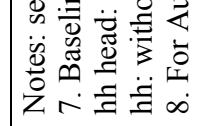

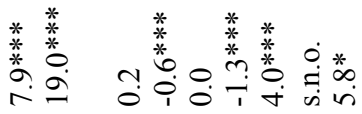

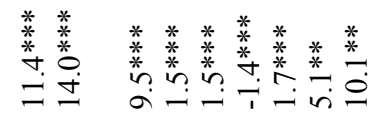

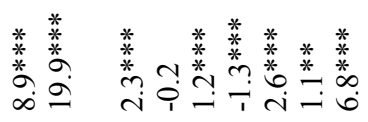

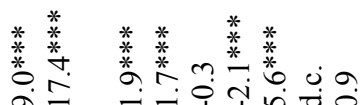

意薏

萃恶

䅈旁

夈菨

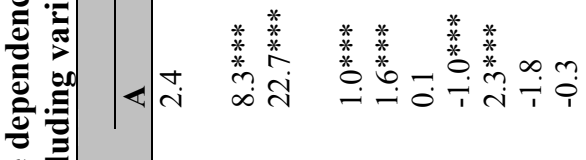

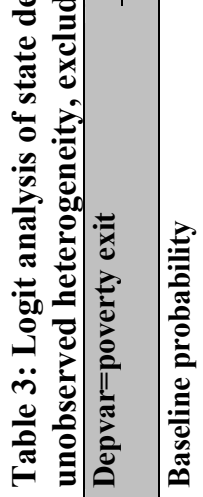

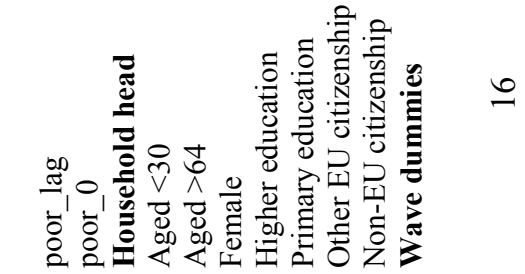




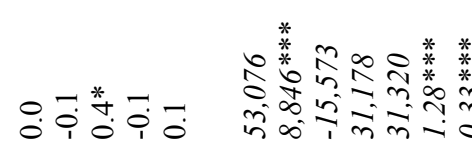

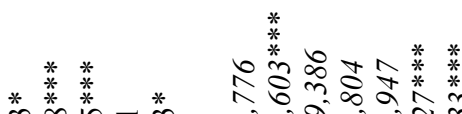
mo

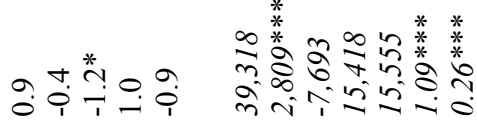
ำำำ

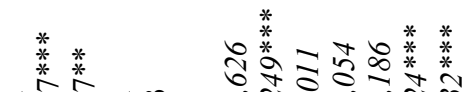

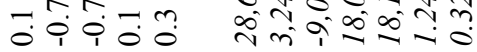

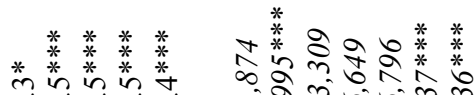

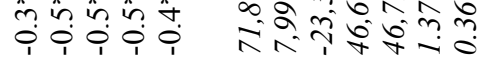

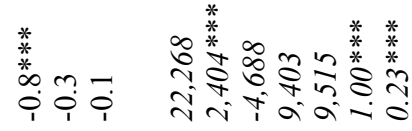

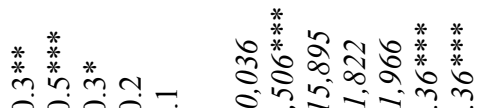

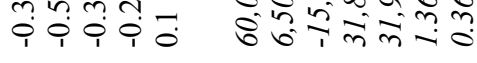

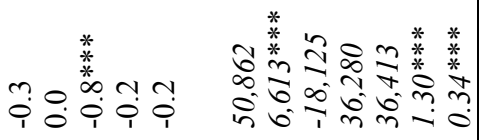
* *

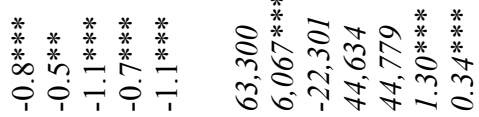

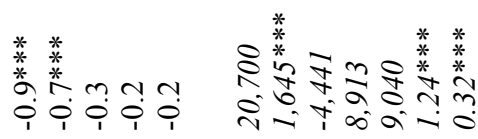

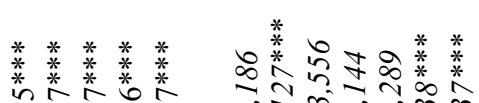

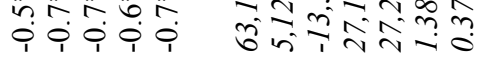

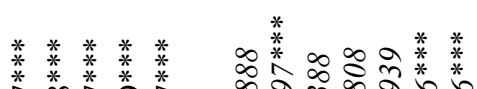

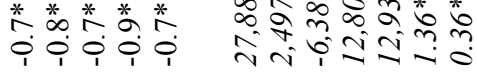

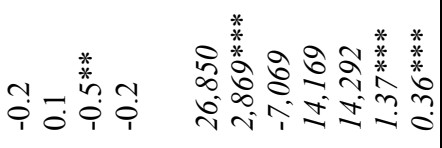

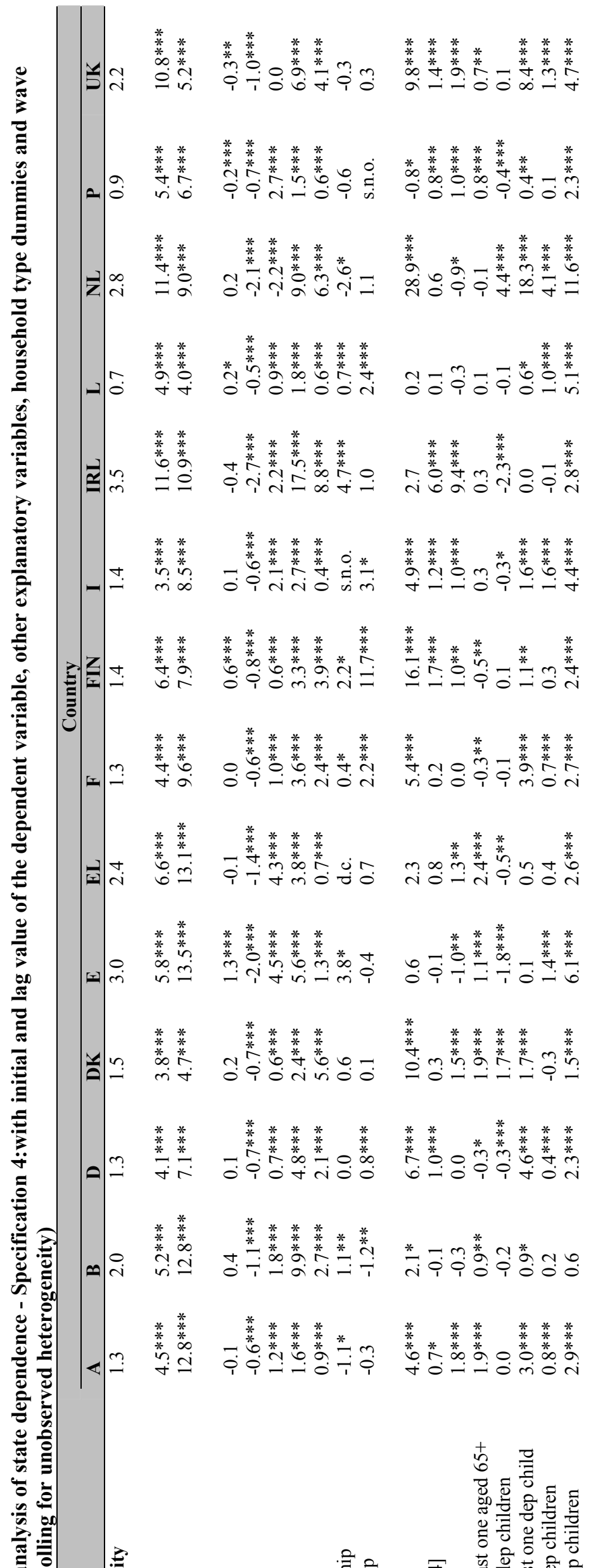

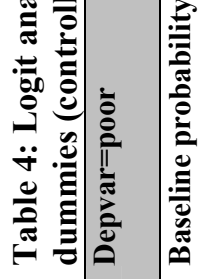

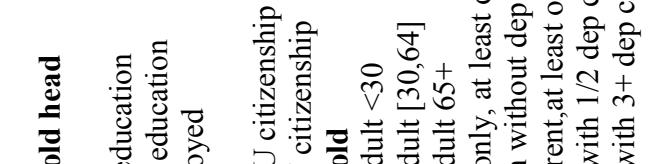

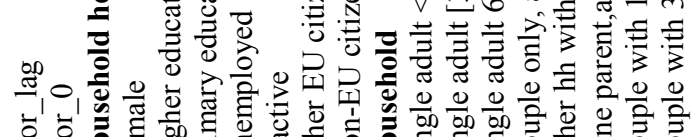

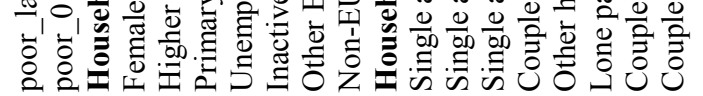




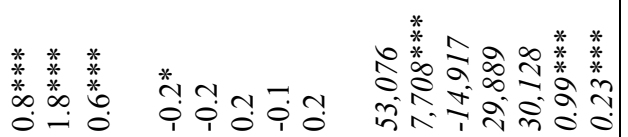

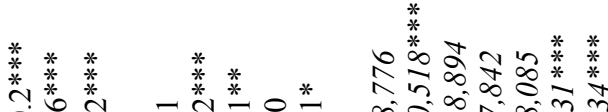
궁

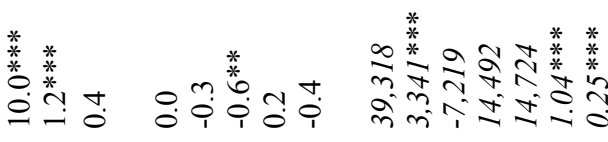

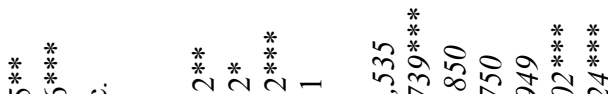

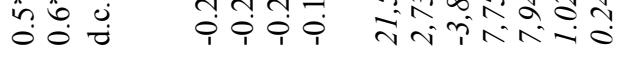

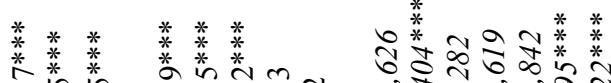

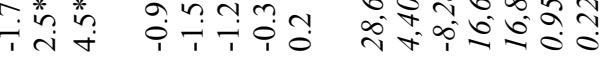

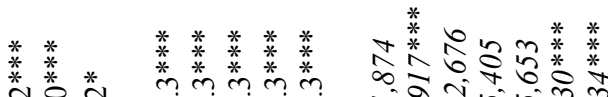

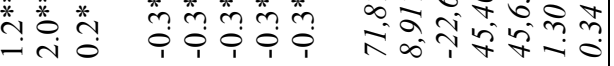

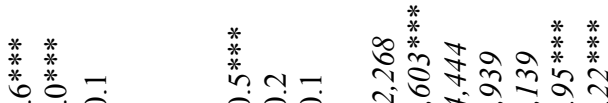

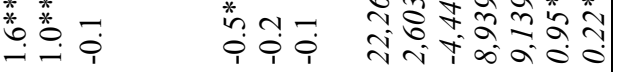

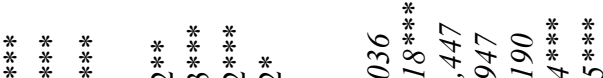

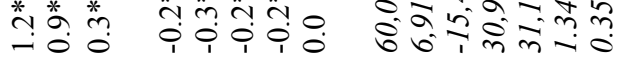

幸菨

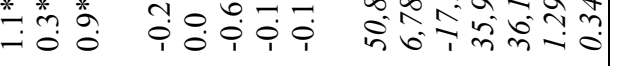

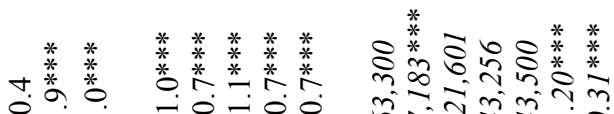

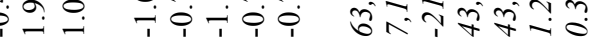

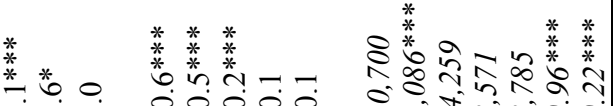

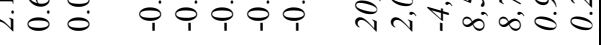

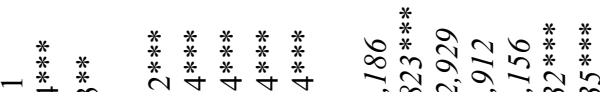
구웡

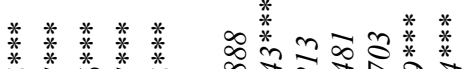

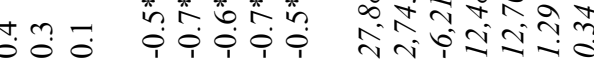

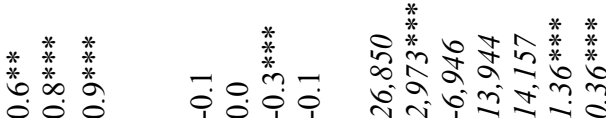

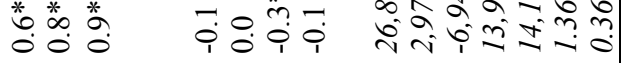

言

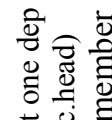

종

产

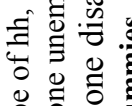

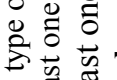

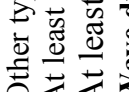

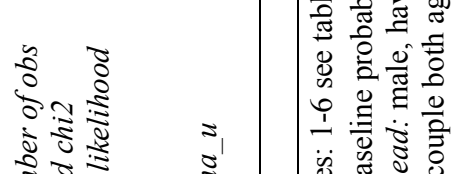

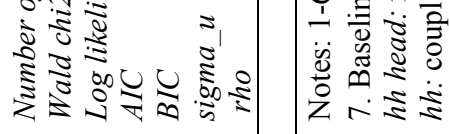

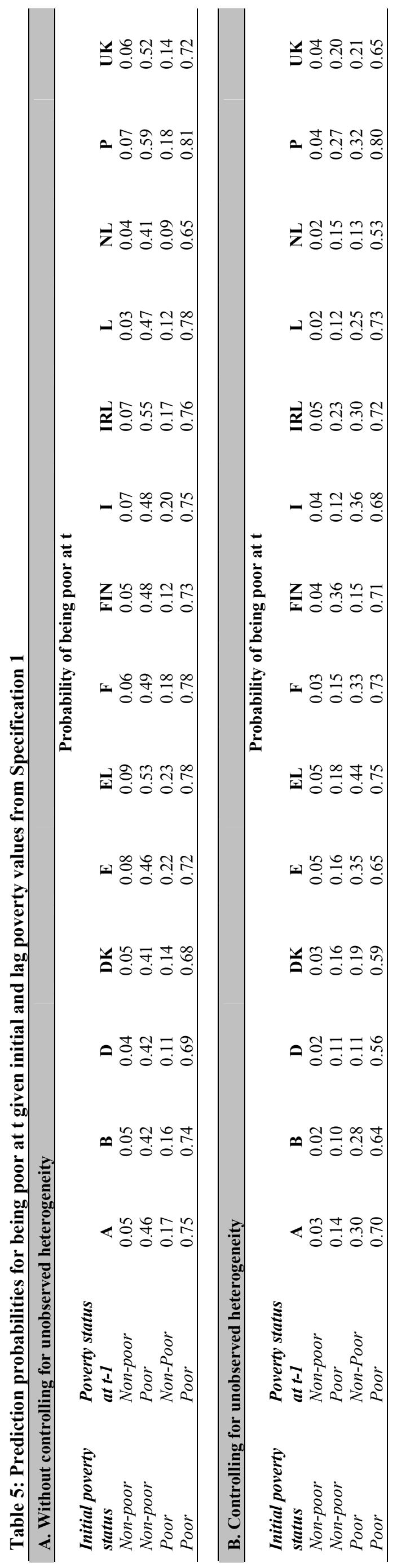




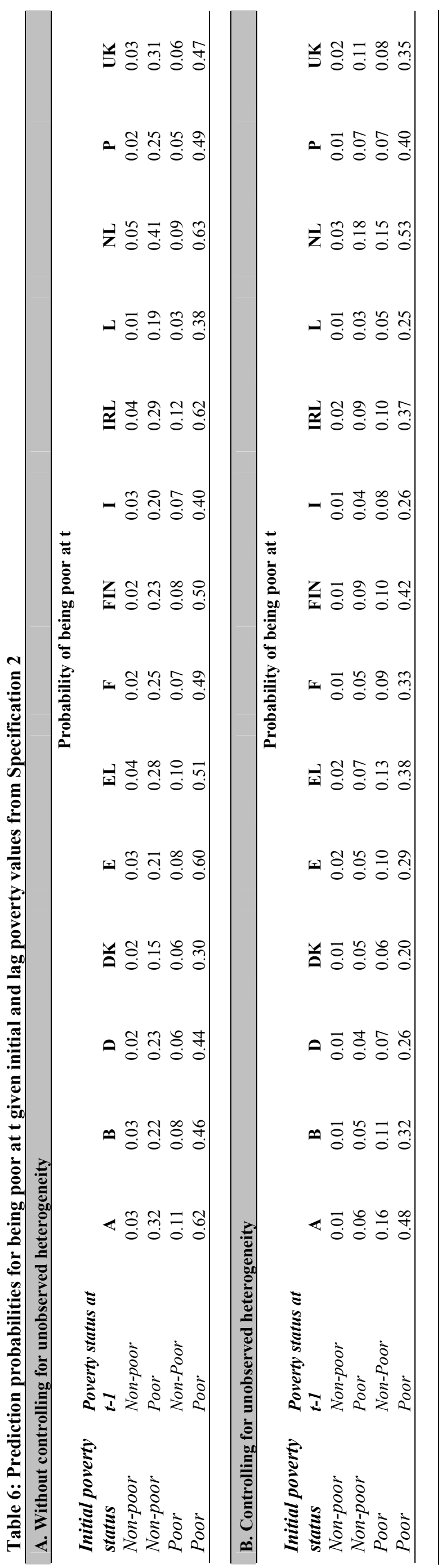

